\title{
MITCHINER MEMORIAL LECTURE* SURGERY IN TROPICAL COUNTRIES
}

\author{
ROBERT W. NEVIN, T.D: \\ Honorary Consulting Surgeon, St. Thomas' Hospital, London
}

FIRST may I thank Sir James Baird for the honour that he has done to me in inviting me to give the seventh Mitchiner Memorial Lecture.

This gives me the opportunity to acknowledge my debt to Philip Mitchiner for all the help and encouragement that he gave to me as a Medical Student at St. Thomas's and as a young surgeon both before and after the Second World War. He took a tremendous interest in young surgeons and must have moulded many careers. He was a very kind and generous man. In the new block about to be opened at St. Thomas's a ward is to be called "The Mitchiner Ward".

More germane to the subject of this lecture-after I had returned to civil life, when the war was over-he encouraged me to give a Hunterian Lecture at The Royal College of Surgeons entitled "The surgical aspects of Intestinal Amoebiasis".

I am very glad that Mrs. Mitchiner is here to hear me say these things about Philip which I do with the greatest sincerity.

The Director-General and I first met in Malta during the war, when he was kind enough to notice my interest in the surgery of tropical conditions and he suggested the title of this lecture. In fact we had a slight difference over the title-a mere quibbleTropical Surgery was suggested. I really felt that there was no such thing, but there are surgical problems that are peculiar to tropical countries.

When war broke out I was more or less a trained general surgeon and had held a surgical scholarship in the United States and Canada. This made me realize that surgical problems were very different in other parts of the world even in so-called temperate countries.

After some experience of Military Surgery in the Dunkirk campaign. I was posted to Iraq where my Consulting Surgeon was that really great man David Fettes, who will be well remembered by many in this room. He had served for years in India and had a marvellous knowledge and experience of tropical conditions. My ignorance was complete and he knew everything that I did not know and from my point of view this partnership was superb.

He had a profound knowledge of Tropical Medicine and a great flare for diagnosis. I shall never forget his diagnosing an amoebic abscess in the left lobe of the liver. I should have failed miserably but he was right and seemed to have supernatural gifts. I am sure that we have all met such clinicians and envied their powers of intuition. The chief burden of this lecture is that we should all acquire as sound a knowledge of Tropical Medicine as possible and that we must all cultivate the art of diagnosis.

A knowledge of Tropical Medicine is the Director-General's province, but how are we to improve our skills in diagnosis?

The art of diagnosis of a case may be defined as a process of logical deduction from the facts elicited both from the history and the demonstrable physical signs in the light of present circumstances and previous experience.

* Given at the Royal Army Medical College, Millbank, London, S.W.1. on 18 November 1975. 
It is not simply a matter of case-matching or logical deduction. Obviously the degree of previous experience is a tremendous variable and no definition can include those who seem to have second sight - a sort of mystique which is quite unusual.

It is probably quite unnecessary to make this plea now-but at the beginning of the last war, when one was seeking for up-to-date knowledge of war surgery and medicine, one could only get a Field Service Pocket Book published in January 1918, price $9 \mathrm{~d}$. One learned a great deal from it but it was twenty years out-of-date. The section on Trench Foot was the most useful thing in it, as far as I was concerned.

There was an immense acquisition of knowledge during the war-the use of antibiotics, the concepts of delayed primary suture and secondary suture and so on.

The European war was over. I was stationed in Italy behind Rimini and was sent up to inspect the German Hospitals Centre at Cesena. The treatment was that of the Field Service Pocket Book of January 1918-rivers of pus, suppurating wounds shut up in plaster and many other horrors. When I told this tale to the local Brigadier R.A., who was stationed in the same town-he said " Their Gunnery was just the same and that is why they lost the war". Anyway whether this last remark be true or not, the point is taken, all new methods must be studied and adopted where appropriate.

The more technical problems of Surgery in Tropical Countries will be discussed under four headings:

(a). Diagnosis. (b) Injuries and battle casualties. (c) The importance of hydration and electrolyte balance. (d) The surgical problems of diseases occurring typically within the tropics.

(a) The importance of diagnosis may again be emphasised by noting that the symptoms and signs of ordinary surgical problems may be greatly accentuated by climate, but also tropical diseases may mimic well known conditions which require relief by surgery.

Malaria is one of the commonest diseases to afflict man. The parasites may be so numerous as to obstruct capillaries and cause congestion and perhaps infarction or even necrosis in any organ-including the brain in cerebral malaria.

This conjures up great difficulties in the diagnosis of head injuries and the acute abdomen and we can only advise the surgeon and apply the maxim when in doubt open the abdomen-with the greatest caution and reference to an experienced Tropical Physician when possible. Latent malaria may be activated by an injury or a surgical operation.

(b) Injuries and battle casualties occurring under tropical conditions must be treated by the accepted surgical methods with a knowledge of the tropical diseases which may affect the patient in the country concerned. The surgeon must be prepared to diagnose and treat these conditions-if uncomplicated-himself. The Consulting Physician will be busier than he is and should only be called in when some unusual problem presents. This is-in no sense-a treatise on Tropical Medicine but one must emphasize again the importance of a knowledge of the diseases occurring in any locality and confirming their presence by the laboratory proof of the appropriate parasite.

(c) The importance of hydration and electrolyte balance cannot be over-emphasized. It is absolutely vital in all surgical procedures before, during and after operation. Salt replacement is most important. Every effort must be made to avoid the occurrence of 
urinary calculi which are apt to form in the dependent parts of the renal pelves during prolonged recumbancy for fractures and other injuries.

(d) I would like to deal with three conditions in some detail:

First-Amoebiasis because of its great importance. Secondly-Typhoid Fever because there is a tendency to ignore it from the surgical point of view. Thirdly-Schistosomiasis because much new work has been done during recent times.

\section{AMOEBIASIS}

\section{Pathology}

Entamoeba histolytica (Nevin 1947) passes through the mucous membrane of the large intestine into the submucous tissue and then produces an inflammatory reaction with oedema but remarkably little leucocytic infiltration.

The centre of the swollen and congested patch, so formed beneath the mucous membrane, typically becomes soft and yellowish as necrosis occurs in its centre. The mucous membrane gives way in the centre and forms an ulcer which has a necrotic floor and shreddy undermined margins. They have been described as bottle-neck or button-hole ulcers on account of the relatively large area of destruction on the submucous space as compared with the actual size of the loss of mucous membrane.

These ulcers may appear as mere pin points or the process may spread in the submucous space and contiguous lesions may become confluent, forming sinuses and eventually large areas of mucous membrane may slough. The ulcers usually extend in the longitudinal axis of the bowel. The larger ulcers have thickened edges, which are considerably raised from the surface of the mucous membrane and are much undermined. The floor of the more recent ulcers is covered with necrotic material, blood and pus. The more chronic ones show a smooth floor.

Histological sections of early and acute cases show that the characteristic lesion is produced by an actual lysis of tissue by the entamoeba. There is remarkably little tissue reaction. This only occurs later when secondary bacterial infection is superadded.

The muscular coats of the bowel may become involved and perforation may occur. When this process occurs, it usually happens gradually so that adhesion to omentum or surrounding structures occurs before the actual perforation takes place. This means that a localized pericolitis or periproctitis with or without abscess formation is much more common than a free perforation into the peritoneal cavity. The lesions may be scattered throughout the large bowel but are frequently confined to the caecal or to the rectosigmoid regions.

Desjardins has made the remark that experience in diagnosis of amoebiasis determines the difference between surgical resection or medical treatment. The possibility of amoebiasis must always be considered in the diagnosis of any unusual abdominal condition in a patient, who is at all likely to have acquired the disease even if no actual dysenteric symptoms are present. It is convenient to consider these abdominal conditions in three groups:

(a) Actual surgical complications of amoebiasis. (b) Amoebiasis simulating other conditions such as: Appendicitis, the Dyspepsias, Intestinal occlusion, Gall stones and Renal stones. (c) Amoebiasis complicating the natural recovery from surgery as in the 
infection and ulceration of wounds in cases of Appendicectomy and the ligature and excision of haemorrhoids.

Individuals with chronic or latent amoebiasis will be generally below par, will usually have a secondary anaemia and appear to be in chronic ill health.

Some authorities state that the majority of persons infected with Entamoeba histolytica do not have dysenteric symptoms. Dysentery is, in fact, only one manifestation of the disease. Many cases present themselves with vague abdominal symptoms and give no history of dysentery at all.

Sapero (1939) states that of a series of 46 patients with non-dysenteric intestinal amoebiasis, 84.8 per cent presented with abdominal pain and 63 per cent had tenderness in the neighbourhood of Mc.Burney's point. It is clear that non-dysenteric amoebiases presents the major diagnostic problem. A patient presenting with dysentery would certainly be suspected of amoebiasis and Entamoeba hystolytica in some form would be recognised in the stools. The absolute diagnosis does and must rest on the demonstration of the amoeba.

In those cases which present with vague abdominal pain or with definite symptoms and signs localized to the right lower quadrant of the abdomen, a saline purge will frequently cause cysts of the amoeba to appear in the stools. A provocative dose of emetine may do the same. These two methods have come to be used because clinical observation has shown that a latent amoebiasis has frequently been brought to light by an attack of enteritis or bacillary dysentery and also if frequent examinations of the stools are made in patients who are receiving a course of emetine as a therapeutic test, the amoeba is quite commonly demonstrated.

\section{Sigmoidoscopic examination}

In about one-third of all cases of amoebiasis there are demonstrable lesions in the rectum or lower sigmoid colon which can be seem with a sigmoidoscope. Four main types of lesion may be recognised:

(a) The frank large ulcer which may be diamond shaped and may be single or multiple and if single or few usually shows a fairly normal mucosa apart from the actual lesions. These ulcers have a raised and ragged margin with overhanging edges and a slough is visible in the floor. Usually the amosba will have been readily demonstrated in the stools of these cases without any difficulty, but if not a specimen of the slough from the floor of one of the ulcers should be examined.

(b) The pin point lesion, which is so often seen on one of the valves of Houston, consists of a raised red area with a greyish white centre. These are often few in number and may be missed unless carefully looked for. Their centres should be scraped with a sharp intrument and examined for the amoeba. Often in these cases the stool examination will have been negative.

(c) "Crateriform Pits" are recognisable in old and quiescent cases of amoebiasis, though the non-activity may only be local. There may be active lesions higher up in the bowel. They consist of small circular depressions about two millimetres in diameter, whose edges are raised up from the surrounding mucosa. It is not usually possible to demonstrate the amoeba in scrapings from these. 
(d) The amoebic granuloma, which usually has an ulcerated surface, is easily confused with a carcinoma. In the cases that I have seen they have been less friable than a carcinoma. A biopsy and a smear should be taken.

The method of collection and examination of the specimens for amoebae taken at sigmoidoscopy is important. A small sharp spoon with a suitably long handle to be introduced into the sigmoidoscope is the best instrument to collect the specimen, which should consist of the actual slough or secretions from the floor of the ulcer. This should be put directly upon a warmed microscope slide and mixed with a little warm saline and a cover-slip should be placed in position and the slide examined as soon as possible.

The value of the white cell count in diagnosis is not really very great. A leucosytosis to $10-20,000$ is usual with about 70 per cent polymorpho-nuclear cells. There may be a slight increase in eosinophiles but this is not a constant finding. The degree of leucocytosis will vary with the extent of any secondary infection that may be present.

\section{The value of radiology in diagnosis}

Druchmann and Schorr (1945) of the Hardassa University of Jerusalem divide the manifestations of amoebiasis in the large intestine into two types. One, the diffuse type, which is not characteristic on $\mathrm{X}$-ray examination and resembles idiopathic or ulcerative colitis. Two, the localized type, which presents a more characteristic picture. These lesions occur, in order of frequency, in the caecum, ascending colon, a sigmoid colon and rectum. They notice the following radiographic differences between these lesions and carcinoma. (a) The filling defect is relatively long in its extent. (b) The lesions are often multiple. Carcinomata may be multiple but very rarely so. (c) The incompleteness of the narrowing as compared with malignant stenosis. Acute intestinal obstruction is rare. (d) The pain which is so typically produced by distension of the stricture by Barium in carcinoma is much less or even absent in this condition. The stricture is less rigid. (e) Freqently, the abnormal area merges very gradually into the normal in this condition. (f) The elasticity of the intestinal wall remains in part and distention of the lumen can be demonstrated on the introduction of Barium. (g) The mucosal relief of the involved portion of the bowel is more or less normal. This emphasizes again the fact that the submucosa is the tissue essentially affected in this condition. (h) The therapeutic test-more or less complete restoration to normal after appropriate specific treatment. (j) Deformity of the caecum is often described as an X-ray finding and given the name of a conical caecum.

\section{Classification of complications}

The classification of complications and sequelae of amoebiasis which are of surgical interest is shown in Table I.

\section{Appendicitis}

We have seen that the caecal region is the commonest site for the chronic and subacute manifestations of amoebiasis. The appendix may be affected by the Entamoeba hystolytica in exactly the same way as the caecum. Clinicai observation seems to show that amoebiasis does not, as a rule, lead to stricture formation in the appendix and so predispose to attacks of obstructive appendicitis. On the other hand, the oedema and general inflammatory reaction produced by an amoebic infection may precipitate an acute exacerbation in a previously diseased appendix. 
Table I

Classification of complications and sequelae of amoebiasis which are of surgical interest

\begin{tabular}{l|l}
\hline \multicolumn{1}{c|c}{ Classification } & \multicolumn{1}{c}{ Classification } \\
\hline Appendicitis & Massive haemorrhage \\
\hline $\begin{array}{l}\text { Ulcerative processes, including those extending beyond the wall } \\
\text { of the bowel and similar processes affecting operation wounds in } \\
\text { the anal canal, etc. }\end{array}$ & Stricture \\
\hline Perforation & Granuloma \\
\hline Pericolitis and pericolic abscess & Haemorrhoids \\
\hline Fistula & Outside the bowel-Hepatitis \\
\hline
\end{tabular}

Cases which present with an infiammatory mass in the right iliac fossa and are treated by the Ochsner-Sherren method can be divided clinically into two types: (a) those which resolve readily, as the ordinary "appendix mass" will do, and (b) those which fail to improve and rather tend to linger and eventually may be shown to clear up when treated with emetine. For completeness, perhaps, the more chronic inflammatory masses in the right iliac fossa such as tuberculosis should be mentioned. Those cases which go on to frank abscess formation require drainage in either case.

The dangers of leaving a case of acute obstructive appendicitis in which there is no clinical evidence of localization are well recognized. There are very considerable dangers and difficulties in removing the appendix in cases of acute amoebiasis involving the caecum and appendix. The tissues are oedematous and friable and any stitch will tear out. A ligature may hold, but satisfactory closure of the stump of the appendix is impossible. I have removed the appendix on one occasion from a patient in this state. A ligature appeared to hold fairly well on the appendix stump. No attempt was made at invagination and a soft rubber drain was placed down to the ligature for forty-eight hours and then gradually withdrawn. The appropriate medical treatment was instituted at once and the patient made an uneventful recovery.

Many deaths have been recorded following appendicectomy for acute infections of the appendix in amoebiasis. The death rate was appallingly high in the famous Chicago epidemic in America in 1933. The deaths were due to faecal peritonitis and wound infections. If operation is undertaken in these circumstances, the most important thing is that the nature of the condition should be recognized and the appropriate specific anti-amoebic treatment instituted.

It may be emphasized again that the greatest danger is to operate upon a case of amoebiasis and to fail to recognize the condition and to institute the appropriate medical treatment. Appendicitis may present in an acute or chronic form. The differential diagnosis in acute cases may be very difficult. The greatest help in diagnosis, as in so many abdominal conditions, is a careful and accurate history. The pain in acute appendicitis usually starts in the epigastrium or centrally. The pain in amoebiasis of the caecal region usually starts in the lower abdomen, when the patient often describes it as going across the lower abdomen, or in the right iliac fossa. Acute appendicitis tends to occur in a person who was previously fit although he may have had previous attacks of a 
similar condition, whereas the symptoms of amoebiasis often present in a person who has been below par for some considerable time. If the case is seen early both history and physical signs may help in the differential diagnosis. In the established case, the physical signs will probably be identical. In the chronic form of the disease, again an accurate history of recurring attacks of pain may help to distinguish appendicitis from amoebiasis, which most typically presents as a thickening or mass, which does not clear up on rest. The best procedure in the doubtful case is to operate, only when there are signs of an unlocalized acute inflammatory process or when emetine has failed. This case of a young soldier of twenty-three illustrates a number of points and serves as example of amoebic Typhilitis, Massive Haemorrhage, Granuloma, and acute intestinal obstructions:-

A young soldier, J.H.G. aged 23 years, while serving in Iraq was admitted to hospital on 1 September 1942.

History-He had been abroad for five months - Capetown, Bombay and Iraq. While on board ship off Capetown five months ago, he was awakened with severe pain across the lower abdomen which radiated to the right loin and settled there. He had no diarrhoea and his symptoms settled completely in twenty-four hours. Two days before admission, pain occurred across the lower abdomen.

State on admission-Temperature, pulse, respiration (T.P.R.) were normal. Indefinite thickening and tenderness in the right iliac fossa. Blood and mucus present in stools. Stools negative for amoebae and dysenteric bacilli. Mass in right iliac fossa became more definite; blood and mucus ceased. Repeated examination of stools normal.

White cell counts are shown in Table II.

Table II

White cell counts

\begin{tabular}{l|c|c}
\hline White cell counts & 3 September 1942 & 18 September 1942 \\
\hline White blood cells & 20,000 & 18,800 \\
\hline Polymorphs & 71 per cent & 79 per cent \\
\hline Small lymphocytes & 20 per cent & 17 per cent \\
\hline Large monocytes & 9 per cent & 3 per cent \\
\hline Eosinophils & 0 per cent & 1 per cent \\
\hline
\end{tabular}

On 29 September 1942, he complained of pain in the back: Runs intermittent fever. T. 100-2, P. 110, R. 20. Mass persists.

On 9 October 1942 his condition was deteriorating. Massive haemorrhage. Typical diamond-shaped ulcers seen with ragged edges. Entamoeba hystolytica demonstrated in scrapings. A course of emetine was commenced, and a blood transfusion (one pint) given.

On 15 October 1942 he was much improved, and on 30 October a Sigmoidoscopy showed that the granuloma had almost disappeared. On 10 November he developed a typical acute attack of small bowel obstruction. At operation the cause of the obstruc- 
tion was a thick oedematous band in the right iliac fossa. This was divided. After operation he improved slowly.

On 21 December 1942 a further course of emetine and amibarsone was given, and on 18 January 1943-No exudate, amoebae or cysts were seen in six successive stools. On 4 February he was evacuated to the United Kingdom as fit.

\section{Ulcerative processes}

Ulcerative processes, including those extending beyond the wall of the bowel and similar processes affecting operation wounds are discussed.

It may be said that all the surgical complications of the condition are associated with an extension of the ulcerative process, which is usually associated.with a secondary infection. The best illustrative case of this condition is one which was admitted to St. Mark's Hospital under the care of Mr. W. B. Gabriel, when I was his house surgeon. It has been reported in the literature (Gabriel 1939) and photographs have been published. The patient was a man of thirty-five who was admitted to hospital in April 1938. He had served in the army as a cook from 1922 to 1928 in India, Mesopotamia, Malta and China. He was not ill during his service and he stated that he had never had any dysenteric symptoms. Three years before his admission to St. Mark's, he developed an abscess in his anal region; which burst and continued to discharge for two and a half years. In January, 1938, he was admitted to another hospital and was found to have a stricture, which just admitted the tip of the finger, three inches above the anus, with friable ulceration below it, which bled freely when touched; there was no induration suggesting a growth. A left iliac colostomy was performed, but in spite of irrigation, the rectal discharge became worse. The ulcerative process spread over the perineum and also appeared and spread around the colostomy. On admission to St. Mark's Hospital, the patient was extremely ill, emaciated and anaemic and was running a swinging temperature. Biopsy fragments from the margins of the ulcerated area showed an intense infiltration of the tissues with inflammatory cells but no evidence of Tuberculosis or Neoplasm. No pathogenic protozoa or cysts were found on examination of the faeces or of scrapings from the ulcerated areas. It was considered that some infective process which originated in the bowel itself must be the cause of this gross ulcerative process affecting two sites at which the bowel reached the body surface, the anus and the anterior abdominal wall at the position of the colostomy. A course of emetine was given with dramatic improvement and also with the appearance of the cysts of Entamoeba hystolytica nine days later. After a course of emetine bismuth iodide and yatrin, all the sloughs had separated and a clean granulating surface remained. After the removal of a necrotic coccyx, this granulating surface was grafted with Thiersch grafts and the patient made an excellent recovery. The colostomy had to be permanent because the anal musculature had sloughed away completely.

Two of my own cases of haemorrhoidectomy in Iraq are very instructive. 1942.

Case 1. T.H. aged 25 years, serving in Iraq was admitted to hospital on 17 September

History-Haemorrhoids for five years, prolapsing recently. He had an attack of diarrhoea for three days in India, but no dysentery was proved. 
State of admission-Had large third degree haemorrhoids. Sigmoidoscopy was normal. On 19 September 1942 he was operated upon-Ligature and excision of three primary haemorrhoids. At first postoperative course was normal. On 19 October 1942 -Anal wounds had not healed, infection and excessive granulation tissue was present.

On 26 October the wounds had increased in size. On 1 November 1942-After repeated examination, cysts of Entamoeba hystolytica were found in the stool and a course of emetine was given. On 9 November the wounds were clean.

On 16 November the wounds were healing rapidly, and on 17 December 1942 he was discharged: healed.

Case 2. A non-commissioned officer aged 30 years, stationed in Iraq, was admitted to hospital on 11 September 1942.

History-He had a seven years history of attacks of rectal bleeding, recently associated with prolapse. Three months ago an investigation for diarrhoea was made in India and no evidence of dysentery was found.

State on admission-He had large third degree haemorrhoids. On 14 September 1942 he was operated upon--Ligature and excision of three primary haemorrhoids.

On 12 October 1942-Anal wounds had increased in size, and were grossly septic. On 2 November-Local conditions were getting worse. Repeated examination for Entamoeba hystolytica proved negative. A course of emetine was given as a therapeutic test.

On December 1942 - Cysts of Entamoeba hystolytica were found in stools and on 25 January 1943 he was discharged to duty as fit.

Amoebic ulceration of the skin and subcutaneous tissues is not a common manifestation and when it occurs it usually appears around the anus or around a colostomy or a wound made for the drainage of an amoebic abscess. A primary cutaneous lesion has been described but is excessively rare. The clinical manifestation of these cutaneous lesions is that of a progressive irregular ulcer with overhanging gangrenous edges, surrounding these edges a pigmented zone; which has been described as a "halo " of a dusky reddish colour which gradually merges into the normal skin. The floor of the ulcer consists of adherent greyish necrotic tissue and the discharge is fetid.

Amoebae are not usually present in the exudate but can often be demonstrated in the tissues beneath the undermined edges of the ulcer. It will be seen that the condition approximates to that of a spreading gangrene of the skin. The prognosis is grave and in one series of twenty-six cases reviewed by Wyatt and Bucholz (1941) the mortality was 32.3 per cent.

\section{Perforation}

Perforation may occur after adhesions have occurred between the site of perforation and the omentum or a neighbouring viscus or it may occur into the free peritoneal cavity. In either event, it will occur in a case of gross and active amoebiasis and in a very ill subject. The most common sites are in the caecal and the recto-sigmoid regions. It is only when there is a faecal flooding into the general peritoneal cavity that a dramatic change will be noted in the physical condition of the patient. There is then collapse, 
rising pulse-rate, distention and abdominal wall rigidity. The more usual condition is that of a perforation into some confined space where adhesions have previously formed. This will produce an increase in local symptoms and signs and will result in a pericolitis or pericolic abscess.

In 1944, Tan and Liu studied twenty cases of autopsy on cases of amoebic dysentery with special reference to perforation. They all occurred in fulminating acute cases. It is doubtful whether laparotomy is ever justified in cases of perforation. It is clearly only indicated in those of free perforation. These patients are always in extremely poor condition and it is very difficult to effect a closure of the perforation on account of the fragility of the tissues. However, there are two cases of successful suture on record.

\section{Pericolitis and pericolic abscess}

Pericolitis and Pericolic Abscess should be treated expectantly with anti-amoebic drugs in the first instance. Later, the abscess may be aspirated or may be drained on the same principles as any other intra-peritoneal abscess if necessary. Anti-amoebic treatment should be continued.

\section{Fistula}

Fistula may occur as a result of perforation or spread of infection in the perianal region. The condition may be associated with gross perianal ulceration as already described. It is important to recognize the amoebic nature of the lesion, apply the specific treatment and then deal with the fistula by the ordinary surgical measures appropriate to its particular anatomy.

\section{Massive haemorrhage}

Massive Haemorrhage may occur in any case of active amoebiasis, but most typically happens when there is gross secondary infection with the formation of sloughs. The separation of these is often associated with gross bleeding. As in all other complications of the disease, its prompt recognition and the prompt administration of specific drugs is the most important thing. Sedatives and blood transfusion should be given as required.

\section{Stricture}

Fibrous stricture results from deep ulceration with secondary infection and is most common in patients who have had recurrent infections over long periods. As already pointed out, these lesions are most common in those areas of the large bowel most usually affected by the disease.

Sacculation of the caecum and ascending colon rarely give rise to any symptoms because of the fluid nature of the intestinal contents at this level and the fact that these strictures are seldom marked. Strictures of the rectum usually occur within reach of the finger and often will only admit the tip of the little finger and are diaphragmatic in their arrangement. They almost certainly follow gross ulceration with secondary infection. Typical amoebic ulcers are frequently seen with the proctoscope or the sigmoidoscope in these cases. 
The correct treatment is to give anti-amoebic drugs first, which are not likely to have any effect upon the fibrous stricture, but it is very dangerous to carry out any surgical procedure until this has been done. Systematic and repeated dilation with posterior proctotomy, when necessary, are then carried out.

One unusual personal case of amoebic stricture may be recorded:-An R.A.M.C. officer was invalided home early in the war with a diagnosis of carcinomal of the transverse colon. He had noticed that his caecum became very distended at times and a barium enema demonstrated a stricture in the transverse colon. He had had very severe Amoebic Dysentery in the Khyber Pass in 1919 and had been very ill indeed. Otherwise, he had been a fit man. At laparotomy two fibrous structures were found in the transverse colon. They seemed to be caused mainly by a pericolic fibrosis and almost certainly represented the result of small perforations with secondary infection. It was possible to carry out plastic procedures without actually opening the lumen of the bowel and the patient made an excellent recovery and had no recurrent bowel symptoms.

\section{Granuloma}

This is not a common manifestation of the disease but is extremely confusing from the point of view of diagnosis. It is very easily confused with carcinoma. The most common situations are the caecal and the recto-sigmoid regions. A mass is felt and a partial or complete obstruction may be present. Mistakes are frequently made in diagnosis unless the condition is kept in mind. The entamoeba may be demonstrated in the stools or a typical lesion may be seen with the sigmoidoscope. On treatment with emetine, the granuloma usually disappears dramatically leaving very little scar tissue. The therapeutic test is therefore very helpful. The ultimate difficulty in diagnosis rests in the fact that a granuloma and a carcinoma may exist together in the same patient and at the same time.

The following cases serve to illustrate the problems involved:-

Gunn and Howard (1931) reported three cases in which the diagnosis of carcinoma was made, one was situated in the caecum, one in the transverse colon and one in the descending colon. Resection was carried out in all the cases. They all proved to be amoebic granuloma and two of them died as a result of operation.

My personal cases are more ordinary but instructive.

In one, a young soldier who presented with a mass in the right iliac fossa which was discrete and slightly tender and who had Entamoeba hystolytica in his stools, the lesion cleared up on emetine.

The other case was a woman of forty-six, who was seen in Out-Patients in London and who had never been out of England. She gave a history typical of carcinoma of the rectum and on examination with a finger there was a firm fixed mass in the upper third of the rectum. Proctoscopy and sigmoidoscopy revealed no ulcers or abnormalities other than the palpable lesion, which was ulcerated and protruded into the lumen of the rectum and involved about two-thirds of its circumference. A clinical diagnosis of carcinoma of the rectum was made and a specimen taken for biopsy was returned as granulation tissue. A further biopsy confirmed this. The stools were searched for amoebae which were found. The mass disappeared completely on a course of emetine.

The chief point in this most important differential diagnosis is that the possibility 
of an amoebic granuloma should be kept in mind even in people who have not lived in the so-called endemic areas.

The usual methods of establishing or excluding a diagnosis of amoebiasis are used. If the therapeutic test has failed in a suspected case, resection may be undertaken, with the giving of further anti-amoebic drugs. This procedure will act as a safeguard in those rare cases where carcinoma and amoebic granuloma co-exist and those rare cases in which an amoebic granuloma does not disappear completely and readily with antiamoebic drugs.

\section{Haemorrhoids}

Haemorrhoids frequently appear or become acutely inflamed as a result of an acute attack of dysentery. It is important to recognize the sequence of events in such cases and treat the dysentery. The haemorrhoids will then subside.

Two cases have already been described of gross prolapsing haemorrhoids in patients with latent amoebiasis. It was seen that the operation wounds became ulcerated and failed to heal until the true nature of the condition was recognized. The amoebiasis should first be treated and then any haemorrhoids that persist may be treated surgically on their merits.

\section{Hepatitis}

Amoebae invade the capillaries and radicles of the portal vein in the submucosa of the bowel wall and are carried to the liver where clots containing amoebae can be found in the lumen of its terminal branches. Confined to this site and widely distributed in small numbers they produce the acute congestion associated with the pre-suppurative stage of hepatitis. If at any point they are sufficiently numerous to produce clotting in a number of contiguous vessels the impediment to the circulation causes necrosis, and the necrotic tissue is invaded by amoebae with production of greyish areas of softening. Extension by concentric layers of softening produces a larger cavity (or cavities) containing reddish brown viscid fluid within walls, the inner surface of which consists of shaggy necrotic tissue. Tissue reaction is at first absent but eventually a fibrous wall limits further destruction of liver tissue, although the abscess may continue to grow in size by the formation of pus from the inner lining of the wall (pyogenic membrane). This fibrous wall is not always formed, and all degrees of reactive change are found, there being little in acute multiple abscesses, and a considerable fibrous wall in chronic single abscesses, of some months duration.

In the slowly developing case with a fibrous wall there may be little enlargement of the liver and no symptoms for some years but enlargement may occur without much further destruction of liver tissue. Rupture may occur into the right pleura or lung. Secondary abscess at the base of the right lung is the most frequent complication. This frequently discharges into a bronchus with considerable amelioration of symptoms. General peritonitis may occur from rupture and rupture may also occur into any adjacent hollow viscus. A localized supra-hepatic or sub-hepatic abscess may arise. An abscess of the left lobe may rupture into the pericardium when sudden death usually results. Occasionally abscesses may become encysted and dry up. This is by no means rare and calcification may occur in the wall of such an abscess. 
If it were possible to diagnose all cases of Amoebic Hepatitis early, medical treatment would avert abscess formation.

The symptoms and signs are very variable. In some cases there will have been no bowel symptoms of any kind. Hepatitis should always be suspected in any vague abdominal condition.

The usual symptoms of hepatic abscess are:-progressive ill-health, weakness, loss of weight and low grade fever-presenting with a muddy complexion, furred tongue, tenderness around the liver, with hepatic enlargement and a tendency to stoop to the right side. There are frequently signs at the base of the chest on the right side.

Sigmoidoscopy may or may not show evidence of amoebiasis and the stools may or may not show amoebae. There is usually a leucocytosis of about 12,000 .

$\mathrm{X}$-rays may show enlargement of the liver with raising of the diaphragm and even a lesion of the base of the right lung. Comparatively recently technetium scans of the liver (Jones 1975) have been used in investigating and localising the lesions in suspected chronic cases.

Medical treatment should be instituted and the liver aspirated through a wide bore needle and the abscess evacuated. If this fails, laparotomy should be performed under emetine cover with external drainage of the abscess.

\section{The treatment of these complications}

It has been seen that in most instances the only treatment required is medical: the giving of the appropriate courses of specific drugs. If, when this has been done, some surgical lesion persists such as an abscess, a fistula, a fibrous stricture, a tumour, which might be a co-incidental carcinoma, a chronically inflamed appendix, or prolapsing harmorrhoids, this surgical lesion may be dealt with by the appropriate operative procedure. Even then it will be advisable to give further anti-amoebic drugs during the postoperative period.

\section{TYPHOID AND PARATYPHOID FEVER}

The diagnosis of these conditions may be very difficult because of previous immunisation and the difficulty of demonstrating serum reactions. The confusion between Typhoid and Malaria and the fact that they may co-exist adds to the difficulties. It is most important to demonstrate the bacillus in blood cultures, stools or urine, if possible.

The third week is the classical time for the well-known complications of haemorrhage and perforation. Haemorrhage is the more common but both are heralded by a rise of pulse rate and collapse.

Perforation usually occurs in the terminal ileum but may occur in the large bowel in Paratyphoid Fever. Perforation may occur without pain but tenderness is usual and a silent and slightly distended abdomen is typical.

During the first week there may be marked symptoms in the right iliac fossa and appendicitis may be suspected when the explanation is really a lymphadenitis or a peri-ileitis. 
A negative laparotomy during the first week may cause little harm but during the third week or later is often fatal and the operative treatment of a perforation carries a very high mortality. The leucopenia of typhoid should caution one against laparotomy and appendicectomy should not be contemplated in any tropical condition unless there is evidence that it is really acute.

The prognosis of operation for perforation during the third week or later is so grave that many feel these cases should be treated with antibiotics, suction and intravenous fluids.

\section{SCHISTOSOMIASIS}

Schistosomiasis is a disease principally of Egypt, other African countries and Iraq. The cercaria larva may gain access to the human body through the skin while bathing or washing or may be ingested in drinking water. Both the common varieties affect principally the liver and here they develop into adult worms and start to produce their eggs. In chronic cases there is fibrosis of the liver-in extreme cases the so-called claypipe stem fibrosis.

Schistosoma mansoni then affects the large bowel and its eggs have a lateral spike. These are most easily demonstrated in scrapings from the floor of the ulcers present in the lower bowel. Chronic granulomatous and ulcerative lesions typically occur in the lower bowel. They are indolent but do not lead to mechanical or malignant complications. It is therefore only of diagnostic interest to the surgeon.

Schistosoma haematobium after becoming established in the liver affects the urinary tract producing granulomatous and ulcerative lesions particularly around the trigone and basal region of the bladder. Deposition of ova and the chronic inflammatory process in turn give place to fibrosis and later bladder neck obstruction (Zaher and El Deeb 1971) and also to obstruction of the lower end of the ureter, causing hydronephrosis. After control with antimony, plastic operations and sphincterotomies have been performed for relief of obstruction.

Carcinoma of the bladder is a well known complication of urinary Schistosomiasis and most commonly occurs on the posterior wall of the bladder (El Boulkany, Ghoneim and Mansour 1972). These cases are found to be radio-resistant squamous celled carcinomata. In 1972 Ghomeim, Mansour and El Boulkany reported a series of 137 cases of radical cystectomy with formation of a rectal bladder for carcinoma of the bladder in Schistosomiasis with a mortality of 14.6 per cent.

Much new work has been done since the last war both in Egypt and Iraq by surgeons and pathologists on the relationship between Schistosomiasis and carcinoma of the bladder.

In Egypt Schistosomiasis is present in 83.1 per cent (Hashem 1961) of cases of carcinoma of the bladder, but there is no association between it and carcinoma of the large intestine, lung, genital organs or any other site.

During recent years in Egypt the incidence of Schistosomiasis has decreased and so has carcinoma of the bladder; other carcinomata have increased.

A series of post-mortems showed Schistosomiasis in many organs but carcinoma only in the urinary tract. 
It is well established that aniline dye workers are prone to develop carcinoma of the bladder in all countries. B Naphthylamine is the substance most injurious.

Nitrate fertilisers are used extensively in the Nile Delta and it was thought that Nitrosamines derived from these may be an important factor in the high incidence of carcinoma in Egypt, but Egypt is only one of many areas in which there is a high incidence of bladder cancer.

In cases of Schistosomiasis affection of the liver is of great importance in connection with the excretion of Tryptophane metabolites. Hashem (1961) states that the induction of bladder cancer appears to be the end result of the combined effects of two long acting sets of factors, both of which are intimately connected with Schistosomiasis infection.

The first of these is the local effect of chronic irritation by worms and ova in the bladder mucosa leading to hyperplastic and pre-cancerous changes.

The second is the release of Tryptophane metabolites into the circulation following local tissue destruction by the parasites and their detoxication by the liver. The liver is often so damaged that it cannot deal with large quantities of these metabolites, but in any event the excess of inactivated Tryptophane metabolites are excreted and concencentrated by the kidney.

Normally toxic and carcinogenic agents are metabolised in the liver by oxidation into Orthoaminophenols which become conjugated with sulphate of glycuronic acid and excreted in the urine.

In cases of chronic Schistosomiasis a mixture of these substances will be excreted into the urine, but the glycuronic acid conjugates will be reactivated by urinary enzymes to release carcinogenic Orthoaminophenols. The repeated and prolonged contact of these carcinogenic agents with the chronically irritated areas results in carcinoma formation.

This very shortened indication of the way these new investigations are proceeding suggests that it should become possible to do much to eliminate the scourge of Schistosomiasis.

It is not yet clear what the precise cause of bladder cancer is in Schistosomiasis. It may well be a combination of various factors. These investigations have been and are being carried out in Egypt and Iraq largely by Fellows of the British Colleges.

\section{CONCLUSION}

I have said very little about surgery. One's plea to surgeons who go to work in tropical countries is simply for an acute clinical and discerning interest in all problems, followed by careful and only very necessary surgery. Philip Mitchiner would approve of this.

One final word-I am assured by a colleague who is a gastro-enterologist in London that it is not uncommon to find an amoebic liver abscess of the chronic and indolent variety in civilians who present with a general debility and perhaps a mild P.U.O. These are people who have travelled long distances by aeroplane to tropical countries on business and perhaps only spend a few days on their travels.

Surgeons who practise only in this country will meet more and more of these people quite apart from the huge immigrant population. 


\section{REFERENCES}

Druckmann, 'A. and Schorr, S. (1945). Amer. J. Roentgenol. 54, 145.

El Boulkany, M. N., Ghonkim, M. A. and Mansour, M. A. (1972). Brit. J. Urol. 44, 561-570.

GABRIEL, W. B. (1939). Proc. roy. Soc. Med. 32, 902.

Ghoneim, M. A., Mansour, M. A. and El Boulkany, M. N. (1972). Brit. J. Urol. 44, 461-466.

GunN, H. and Howard, N. J. (1931). J. Amer. med. Ass. 97, 166.

HASHEM, M. (1961). J. Egypt. med. Ass. 44, 857.

Jones, R. W. (1975). Proc. roy. Soc. Med. 68, 593.

Nevin, R. W. (1947). Ann. roy. Coll, Surg. Engl. 1, $69-84$.

SAPERO, J. J. (1939). Amer. J. trop. Med. 19, 497.

TAN, C. C. and LUi, Y. (1944). China. med. J. 62, 366.

Wyatt, T. E. and Buchholz, R. R. (1941). Ann. Surg. 113, 140.

ZAHER, M. F. and El DeEB, A. A. (1971). J. Urol. 106, 257-261.

\section{NEW YEARS HONOURS LIST, 1976}

The following awards were published in the London Gazette on 1 January 1976.

C.B. Major-General E. L. O. Hood, late R.A.M.C. Brigadier H. Cattanach, Q.A.R.A.N.C.

O.B.E. Lieutenant-Colonel B. C. McDermott, R.A.M.C. Lieutenant-Colonel K. P. Walker, R.A.M.C., T.A.V.R.

M.B.E. . Major M. Stephens, Q.A.R.A.N.C.

B.E.M. S/Sgt. D. Mitchell, R.A.M.C., T.A.V.R.

R.R.C. Colonel K. Grimshaw, Q.A.R.A.N.C. Colonel D. F. Liddington, Q.A.R.A.N.C. Lieutenant-Colonel J. G. Munro, Q.A.R.A.N.C., T.A.V.R.

\section{Appointments to The Queen}

Colonel (Acting Brigadier) H. A. J. Reay, M.B., Ch.B., F.R.C.P., late R.A.M.C., was appointed Honorary Physician to The Queen, with effect from 3 January 1976, in succession to Major-General E. L. O. Hood.

Colonel (Acting Brigadier) R. G. Emerson, M.B., Ch.B., M.D., F.R.C.O.G., late R.A.M.C., was appointed Honorary Surgeon to The Queen, with effect from 21 January 1976, in succession to Major-General J. E. Miller. 